$33^{\circ}$ Agneau élevé au latt de vache. - Agneau trouvé sur la route, élevé au biberon par Mme Bus, rue de Croze, à Pertuis (Vaucluse).

340 Chien éleví au latt condensé. - "Joli ", chien berger malinois, appartenant à M. Segond au petit Cornarel, à Pertuis (Vaucluse) a été élevé au lait condensé Nestlé additionné d'eau. On commença par lui donner ee liquide au biberon dans sa corbeille et il tétait tout seul. Dès qu'il put boire, on lui donna le lait à l'assiette.

$35^{\circ}$ Petits chiens élevés par des femmes. - Les exemples sont nombreux de petits chiens allaités par des femmes pendant quinze jours, trois semaines. Le cas se produit assez souvent dans nos campagnes, où des femmes perdant leur enfant à la naissance, se font téter par ur jeune chien en attendant un nourrisson. La période d'allaitement ne peut guère être prolongée au delà du temps où les dents de l'animal grossissent. Nous avons vu à l'Ecole Vétérinaire de Lyon un jeune chien nourri dans ces conditions et qui se portait fort bien.

\title{
RECHERCHE DE L'EAU OXYGÉNÉE DANS LES LAITS PASTEURISÉS
}

\author{
par A. TAPERNOUX,
}

Chef de travaux de Chimie à l'Ecole Vétérinaire de Lyon.

Les réactions les plus sensibles qui permettent de rechercher les laits additionnés d'eau oxygénée sont les réactions distasiques. Malheureusement ces réactions sont inapplicables aux laits pasteurisés à 85 ou $90^{\circ}$ et aux laits bouillis, les diastases étant détruites à ces températures.

J'ai pu régénérer dans le lait pasteurisé la diastase oxydante par addition d'un peu de salive, de sorte que la caractérisation de l'eau oxygénée est devenue possible par la réaction classique de Dupour.

Conditions des expériences. - J'ai opérésur du lait qui avait subi la pasteurisation haute, c'est-à-dire qui avait été soumis pendant quelques minutes (deux à six) à la température de $85^{\circ}$. L'eau oxygénée employée était à 12 volumes et chaque série d'expériences a été réalisée avec les doses suivantes, qui sont faibles : 4 cc.-2 cc. et 1 cc. par litre de lait. L'échantillon témoin m'a toujours donné, dans chaque cas, une réaction négative. Dans la première expérience, le lait a été conservé à la glacière. Dans la deuxième expérience le lait a été laissé à la température du laboratoire. Enfin, une troisième expérience comparative a été effectuée sur du lait cru, bien entendu sans addition de salive. Les éshantillons ont été examinés plusieurs fois, jusqu'à la disparition de la réaction positive. 


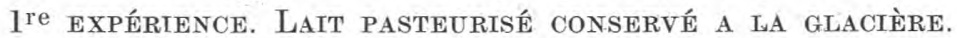

$13 / 9$

8 h. $30 \quad 16 \mathrm{~h} . \quad 18 \mathrm{~h} . \quad 8 \mathrm{~h} .30$

1 p. $1000 \ldots \ldots \ldots+$.

4 p. $1000 \ldots \ldots \ldots+$

2 p. $1000 \ldots \ldots++$
$14 / 9$

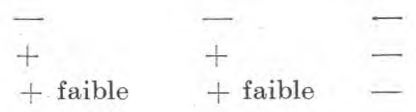

2e expérience. Lait pasteurisé conservé au Laboratoire. $14 / 9$

$15 / 6$

9h. 4510 h. 55 11h. 30 12h. 13 h. 14 h. 16 h. $30 \quad 18$ h. $20 \quad 8$ h. 16 h.

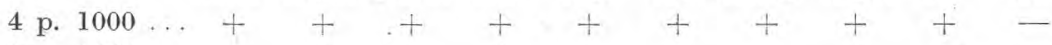

2 p. $1000 \ldots+4+4+\ldots+\ldots$

1 p. $1000 \ldots++$ + + faible - - -

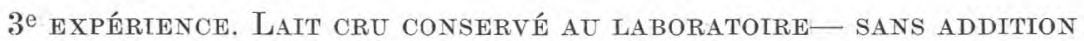
DE SALIVE.

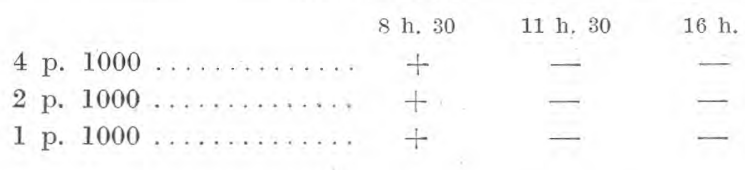

Technique de la racherche. - A 5 ce. de lait pasteurisé, on ajoute environ $1 \mathrm{cc}$. de salive résente; puis $5 \mathrm{cc}$. de solution aqueuse de gaïacol à $1 \%$. On agite bien et on porte au bain-marie à $40^{\circ}$ pendant quelques minutes. La présence de l'eau oxygénie se traduit par une coloration saumon rosé caractéristique, mais je note en passant que la coloration, quoique très nette, est moins intense qu'avec les laits crus.

Remarques. - $1^{\circ} \mathrm{Il}$ est prudent d'essayer au préalable la salive employée au cas peu fréquent, mais possible, ou elle ne contiendrait pas d'oxydase.

$2^{\circ}$ On pəut remplacer la salive par 1 cc. de lait cru dépourvu d'eau oxygénée, lorsqu'on en a à sa disposition.

Conclusions. - $1^{0}$ La réaction désrite permet de déceler l'eau oxygánáz très simplement et très aisément à des doses auxquelles la racherche purement chimique serait malaisée, sinon impossible.

$2^{\circ}$ L'eau oxygénée se décompose dans les laits pasteurisés comme dans les laits crus, mais avec beaucoup moins de rapidité. 